\title{
Chemical Synthesis of Brasilicardins
}

\author{
Fumihiko Yoshimura $^{1 *}$, Ryusei Itoh $^{2}$, Makoto Torizuka ${ }^{2}$, Genki Mori $^{3}$, and Keiji Tanino ${ }^{3 *}$ \\ ${ }^{1 *}$ School of Pharmaceutical Sciences, University of Shizuoka \\ 52-1 Yada, Suruga-ku, Shizuoka 422-8526, Japan \\ ${ }^{2}$ Graduate School of Chemical Sciences and Engineering, Hokkaido University \\ Kita-10 Nishi-8, Kita-ku, Sapporo 060-0810, Japan \\ ${ }^{3 *}$ Department of Chemistry, Faculty of Science, Hokkaido University \\ Kita-10 Nishi-8, Kita-ku, Sapporo 060-0810, Japan
}

(Received June 25, 2020; E-mails: fumi@u-shizuoka-ken.ac.jp (F.Y.); ktanino@sci.hokudai.ac.jp (K.T.)

\begin{abstract}
Brasilicardins A-D, isolated from the culture broth of the actinomycete Nocardia brasiliensis IFM 0406, constitute a class of natural products with a unique structure consisting of a highly strained tricyclic terpenoid core with the central ring in the boat conformation, an amino acid, and a mono- or disaccharide. These molecules display potent immunosuppressive activities and their intriguing biological and structural aspects make brasilicardins attractive synthetic targets. In 2018, we achieved the total synthesis of all brasilicardins AD. In this account, our efforts toward the completion of a unified total synthesis of brasilicardins are described, focusing on the development of methodologies directed towards construction of the characteristic tricyclic terpenoid core, which represents the most critical and challenging task of the chemical synthesis.
\end{abstract}

\section{Introduction}

Natural products produced by microorganisms have contributed tremendously to the improvement of human health over the last 50 years. Actinomycete and fungal strains are known to produce various bioactive secondary metabolites in their culture broths. Brasilicardins A-D (1-4) are bacterial diterpenoid natural products isolated from the culture broth of the actinomycete Nocardia brasiliensis IFM 0406, and they exhibit diverse biological activities, such as immunosuppressive, and antitumor activities (Figure 1). ${ }^{1}$ Among the congeners, brasilicardin A (1) displays the most potent immunosuppressive activity $\left(\mathrm{IC}_{50}, 0.057 \mu \mathrm{g} / \mathrm{mL}\right)$. Although the mode of action of $\mathbf{1}$ has not been elucidated in detail, it is suggested that the immunosuppressive activity of $\mathbf{1}$ is induced by amino acid deprivation, via the inhibition of the amino acid transporter system L. ${ }^{2}$ Because the immunosuppressive mechanism of 1 differs from that of current clinical drugs, such as tacrolimus (FK-506) and cyclosporine A, which inhibit interleukin2 production via the inhibition of calcineurin of helper $\mathrm{T}$ cells and often cause side effects, such as nephrotoxicity and arterial hypertension, $\mathbf{1}$ is considered as a promising drug candidate. Thus, $\mathbf{1}$ has been intently studied, particularly in relation to the development of a novel type of immunosuppressive drug. However, further biological and pharmacological investigations of $\mathbf{1}$ have not been performed due to the scarcity of $\mathbf{1}$ derived from its natural source. Therefore, efficient chemical syntheses of 1, as well as of its derivatives, simplified analogs, and probe molecules, are essential for further studies.

As shown in Figure 1, brasilicardins A-D (1-4) possess a common and highly strained anti-syn-anti-fused perhydrophenanthrene-diterpenoid carbon framework (the ABC-ring), containing two angular methyl groups with the central B-ring in the boat conformation. Various amino acid and sugar units can be attached to this framework.

The combination of their distinctive biological and pharmacological properties and unique complex chemical struc- tures renders brasilicardins (1-4) attractive and challenging targets for synthetic organic chemists. Indeed, several research groups have engaged in extensive synthetic studies of brasilicardins over the last two decades. ${ }^{3}$ However, their complex and unique three-dimensional structure severely hampers their concise chemical syntheses.

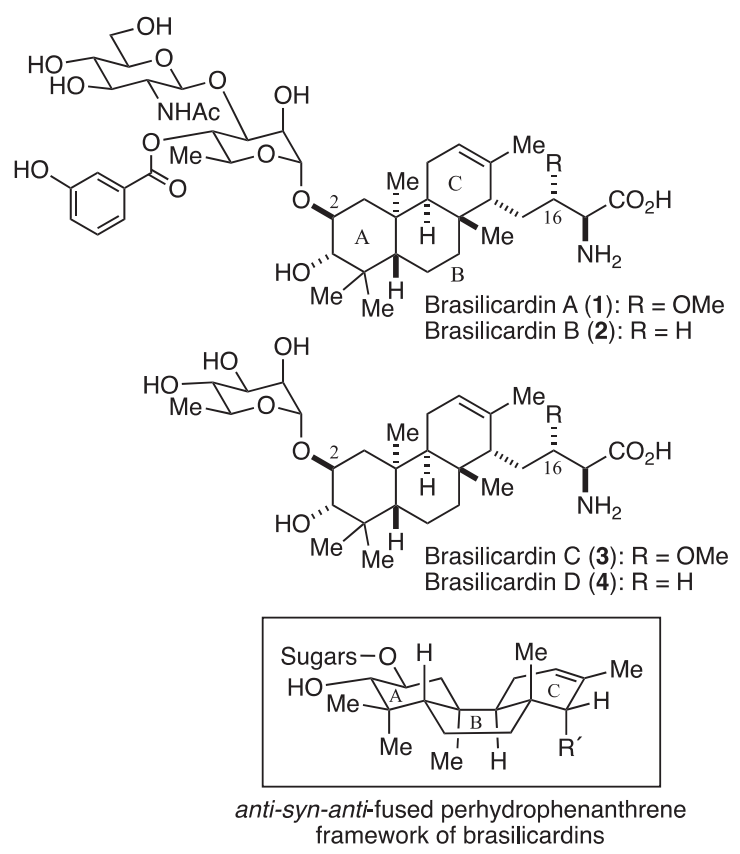

Figure 1. Structures of brasilicardins A-D (1-4).

Prior to our total synthesis, Anada and Hashimoto's 2017 syntheses of $\mathbf{1}$ and $3,{ }^{4}$ highlighted by a Diels-Alder reaction/ reductive angular methylation sequence ${ }^{3 a}$ for the construction of the ABC-ring (Scheme 1), represented the sole successful total synthesis of brasilicardins. We began our synthetic studies of brasilicardins in 2008, aiming for the development of an efficient route that was sufficiently flexible to provide access to 
all of the brasilicardins A-D (1-4), while allowing for the synthesis of various analogs and substructures for biological testing. We achieved the total syntheses of $\mathbf{1 - 4}$ in 2018, including the first total syntheses of $\mathbf{2}$ and $4 .^{5}$ Herein, our endeavor towards a unified total synthesis of all brasilicardins is described, focusing principally on the development of methodologies directed toward the construction of the characteristic tricyclic terpenoid core (the $\mathrm{ABC}-$ ring).

Scheme 1. The Anada-Hashimoto synthetic approach for the total synthesis of brasilicardins A (1) and C (3).

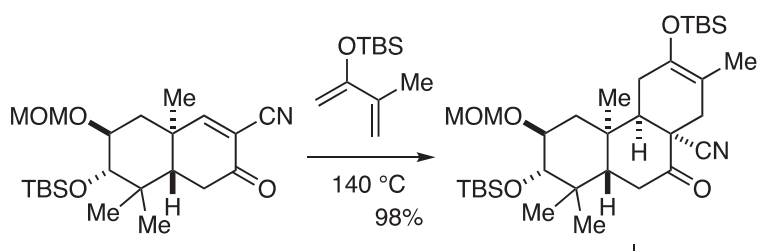
$\mathrm{LiC}_{10} \mathrm{H}_{8} \downarrow-78{ }^{\circ} \mathrm{C}$

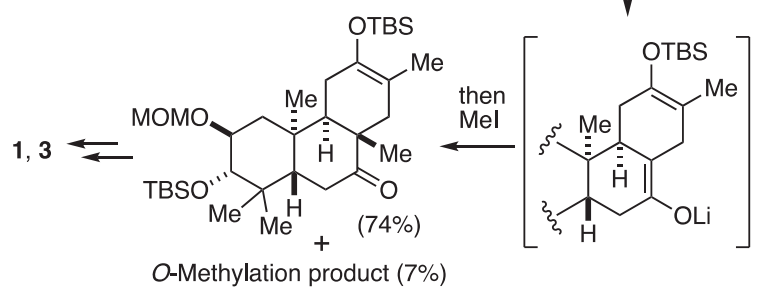

\section{Challenges and Strategies}

Synthetic challenges posed by brasilicardins (1-4) are as follows.

1) The development of a stereoselective synthetic methodology for the highly strained carbocyclic framework containing two quaternary asymmetric carbon atoms at the ring junctures (the ABC-ring system), a pivotal factor in the synthesis.

2) The construction of the amino acid component.
3) Regio- and stereoselective glycosylation of the sugar unit.

4) The overall protecting group strategy for attaining an efficient synthesis.

In order to conduct in-depth structure-activity relationship (SAR) studies to understand the mode of action of $\mathbf{1}$ on a molecular level, and determine the brasilicardin pharmacophore, our strategy was to construct each ring of the carbocyclic framework, as well as the amino acid and saccharide components, in a step-by-step manner. Although a biomimetic polyene cyclization represents a potential strategy for the generation of a polycyclic terpenoid framework, ${ }^{6}$ a previous study had revealed that such an approach was extremely difficult. ${ }^{7}$ Our pivotal synthetic strategy method entailed the design of an intramolecular conjugate addition (Michael addition) of $\alpha, \beta$-unsaturated Weinreb amides ${ }^{8}$ bearing an alkanenitrile sidechain $(\mathbf{5} \rightarrow \mathbf{7}$, Scheme $2 \mathrm{a})$. Despite the poor reactivities of both $\alpha, \beta$-unsaturated Weinreb amides and $\alpha$-cyano carbanions generated from non-activated simple alkanenitriles as Michael acceptors and Michael donors, ${ }^{9}$ respectively, we expected that such a Michael addition would occur smoothly, as the putative stable intermediate $\mathbf{6}$ formed upon addition would prevent unfavored reversible retro-additions. In this regard, we have previously reported an alternative approach for the prevention of analogous retro-additions, via trapping of the intermediate as the corresponding ketene silyl acetal in an intramolecular Michael addition of $\alpha, \beta$-unsaturated lactones. ${ }^{10}$ Additionally, if such additions proceeded with facial discrimination, the significantly less sterically demanding cyano group ${ }^{11}$ would induce the stereoselective cyclization, which would result in the simultaneous construction of contiguous quaternary-tertiary asymmetric stereocenters. Furthermore, the potentially different reactivities between the sterically congested cyano group at the ring juncture and the Weinreb amide group in the cyclization product 7, would facilitate further transformations.

Scheme 2. Retrosynthetic analysis of brasilicardins (1-4).

a

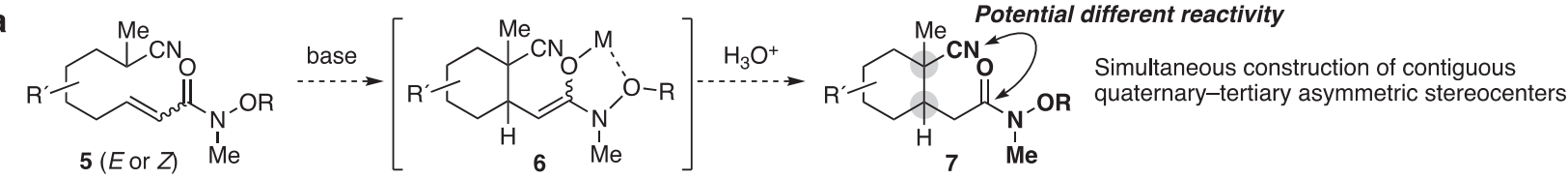

b

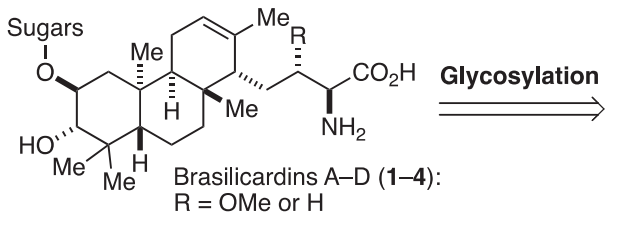

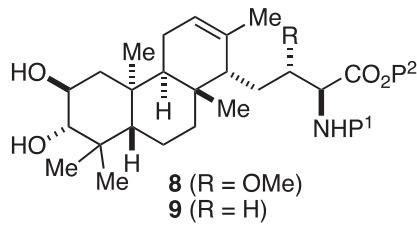

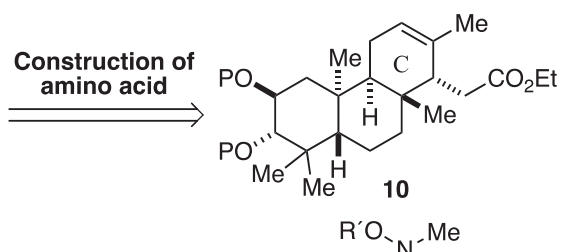

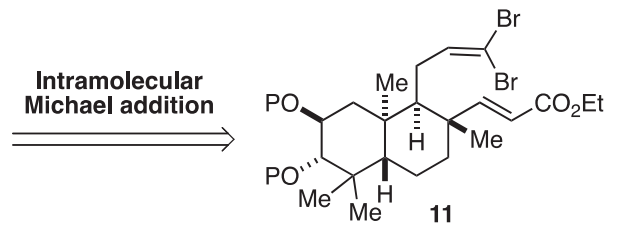<smiles>C=CC</smiles>

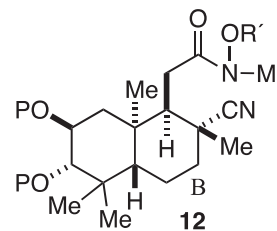

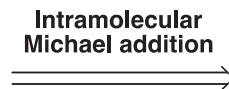

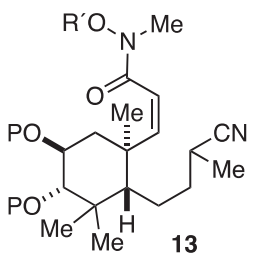

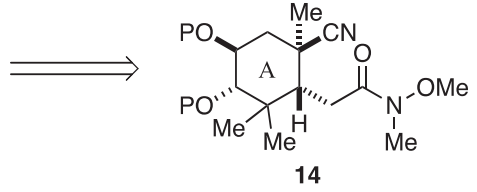

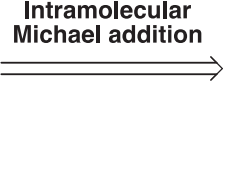

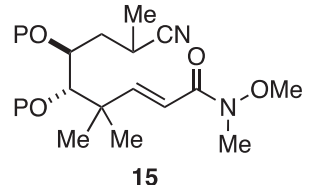<smiles>C=CC(C)(C)CO</smiles>

15 


\section{Retrosynthetic Analysis}

Taking the above-discussed factors into consideration, our retrosynthetic analysis of brasilicardins A-D (1-4) is shown in Scheme $2 b$. The labile sugar unit was attached via regio- and stereoselective glycosylation from the protected aglycons $\mathbf{8}$ or $\mathbf{9}$ at the final stage of the synthesis. Aglycons $\mathbf{8}$ or $\mathbf{9}$ were derived from ester $\mathbf{1 0}$ through construction of the amino acid component. Thus, we envisioned that tricycle $\mathbf{1 0}$ could serve as an important advanced intermediate for the unified total synthesis. The requisite compound $\mathbf{1 0}$ was accessed via a Michael addition-based strategy. More specifically, $\mathbf{1 0}$ could be obtained from $\alpha, \beta$-unsaturated ester 11 through our novel methylative intramolecular Michael addition promoted by the Gilman reagent $\left(\mathrm{Me}_{2} \mathrm{CuLi}\right){ }^{12}$ 1,1-Dibromoalkene $\mathbf{1 1}$ could be synthesized from bicycle $\mathbf{1 2}$ via homologation of the side chains. The B-ring could be constructed through an intramolecular nitrile Michael addition of $(Z)-\alpha, \beta$-unsaturated Weinreb amide 13, as mentioned in section 2 (see Scheme 2a). Amide 13 was derived from cyclic nitrile 14. Again, the A-ring could be constructed by a similar intramolecular nitrile Michael addition of $(E)-\alpha, \beta$-unsaturated Weinreb amide 15, which could be accessed from commercially available 2,2dimethylpropane-1,3-diol (16).

\section{Construction of the $\mathbf{A B}$-ring}

The synthesis commenced with the preparation of the $\alpha, \beta-$ unsaturated Weinreb amide 21, required for the first intramolecular nitrile Michael addition (Scheme 3). Thus, monosilylation of 2,2-dimethylpropane-1,3-diol (16) with $\mathrm{NaH}$ and $\mathrm{TBSCl}$, followed by Swern oxidation of the remaining alcohol gave the corresponding aldehyde, which underwent a one-pot Horner-Wadsworth-Emmons (HWE) olefination under Masamune-Roush conditions (DBU and $\mathrm{LiCl})^{13}$ to furnish $(E)-\alpha, \beta$-unsaturated ester $\mathbf{1 7}$ as the sole product. The asymmetric dihydroxylation of $\mathbf{1 7}$ proceeded optimally with the use of dihydroquinine-based $9^{\prime}$-phenanthryl ether ligand (DHQ) $\mathrm{PHN},{ }^{14}$ to produce the optically active diol $\mathbf{1 8}$ quantitatively ( $95 \%$ ee). Protection of the diol in $\mathbf{1 8}$ with methoxymethyl (MOM) groups, followed by reduction of the ethyl ester with $\mathrm{LiAlH}_{4}$, and iodination of the resulting primary alcohol with $\mathrm{I}_{2}$ and $\mathrm{PPh}_{3}$, yielded alkyl iodide 19. Alkylation of $\mathbf{1 9}$ with the $\alpha$-cyano carbanion derived from propionitrile, and subsequent desilylation, afforded alcohol 20. This compound underwent sequential tetrapropylammonium perruthenate (TPAP) oxidation $^{15}$ and HWE olefination to give $(E)-\alpha, \beta$-unsaturated Weinreb amide 21, the substrate for the key intramolecular Michael addition.

With Weinreb amide $\mathbf{2 1}$ in hand, we then focused on the intramolecular Michael addition for the formation of the Aring (Scheme 3). After an extensive investigation of reaction conditions, we found that when a THF solution of 21 was treated with sodium bis(trimethylsilyl)amide (NaHMDS) at $-78{ }^{\circ} \mathrm{C}$, intramolecular Michael addition proceeded smoothly with complete stereoselectivity, to furnish the desired product 22 in 93\% yield as a single isomer. The use of similar bases, such as LiHMDS and KHMDS, resulted in lower yields of 22. The stereochemistry of $\mathbf{2 2}$ was unambiguously determined by nuclear Overhauser effect (NOE) experiments. The complete stereocontrol observed in $\mathbf{2 2}$ presumably arises as a consequence of chelation control, wherein the keteniminate and $\alpha, \beta$-unsaturated Weinreb amide were both oriented equatorially with an antiparallel dipolar rearrangement in the transition state model TS-1.

Scheme 3. Synthesis and cyclization of $(E)-\alpha, \beta$-unsaturated Weinreb amide 21.
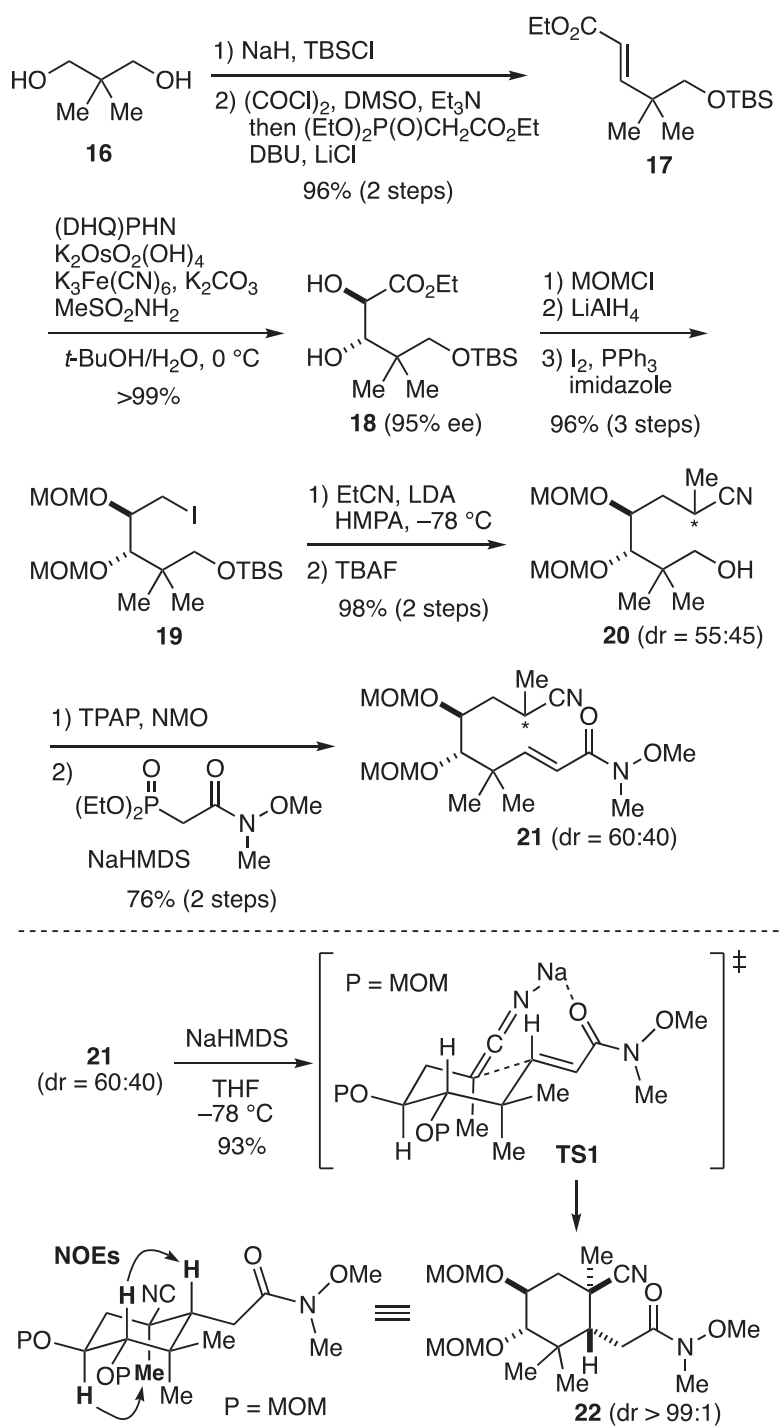

The successful realization of the intramolecular nitrile Michael addition step led us to the next phase of the synthesis, namely, the construction of the B-ring (Scheme 4). Thus, chemoselective reduction of the Weinreb amide over the cyano group in $\mathbf{2 2}$ was accomplished with diisobutylaluminum hydride (DIBAL) in THF, and the subsequent one-carbon homologation of the resulting aldehyde by a Wittig reagent, gave enol methyl ether 23. It is important to note that the use of THF as a solvent in the DIBAL reduction of $\mathbf{2 2}$ was indispensable for achieving a high level of chemoselectivity. Compound 23 was further converted to terminal alkene 25 by a four-step sequence: 1) hydrolysis of the enol methyl ether, 2) Wittig olefination of the resulting aldehyde, 3) reduction of the cyano group to an aldehyde, and 4) reduction of the resulting aldehyde to a primary alcohol. The introduction of a cyano group to $\mathbf{2 5}$ was achieved by a cobalt-catalyzed hydrocyanation with tosyl cyanide (TsCN), according to Carreira's procedure, ${ }^{16}$ to give secondary nitrile $\mathbf{2 7}$ in a regioselective manner. 
Oxidation of alcohol 27 with TPAP gave the corresponding aldehyde, which was treated with Ando's reagent 28 via an HWE reaction ${ }^{17}$ to afford $(Z)-\alpha, \beta$-unsaturated ester 29 with excellent $Z$-selectivity $(Z / E>99: 1)$. Ester 29 was directly converted to $O$-methyl Weinreb amide 30 with the magnesium amide generated from $\mathrm{MeONHMe} \cdot \mathrm{HCl}$ and $i-\mathrm{PrMgCl} .{ }^{18} \mathrm{On}$ the other hand, the sterically demanding $O$-tert-butyl Weinreb amide 31 was also synthesized from 29 via saponification and subsequent condensation of the resulting carboxylic acid with $N$-methyl-O-tert-butylhydroxylamine. ${ }^{19}$ These two cyclization precursors, $\mathbf{3 0}$ and $\mathbf{3 1}$, were utilized in the ensuing B-ring formation.

Scheme 4. Synthesis of $(Z)-\alpha, \beta$-unsaturated Weinreb amides 30 and 31.
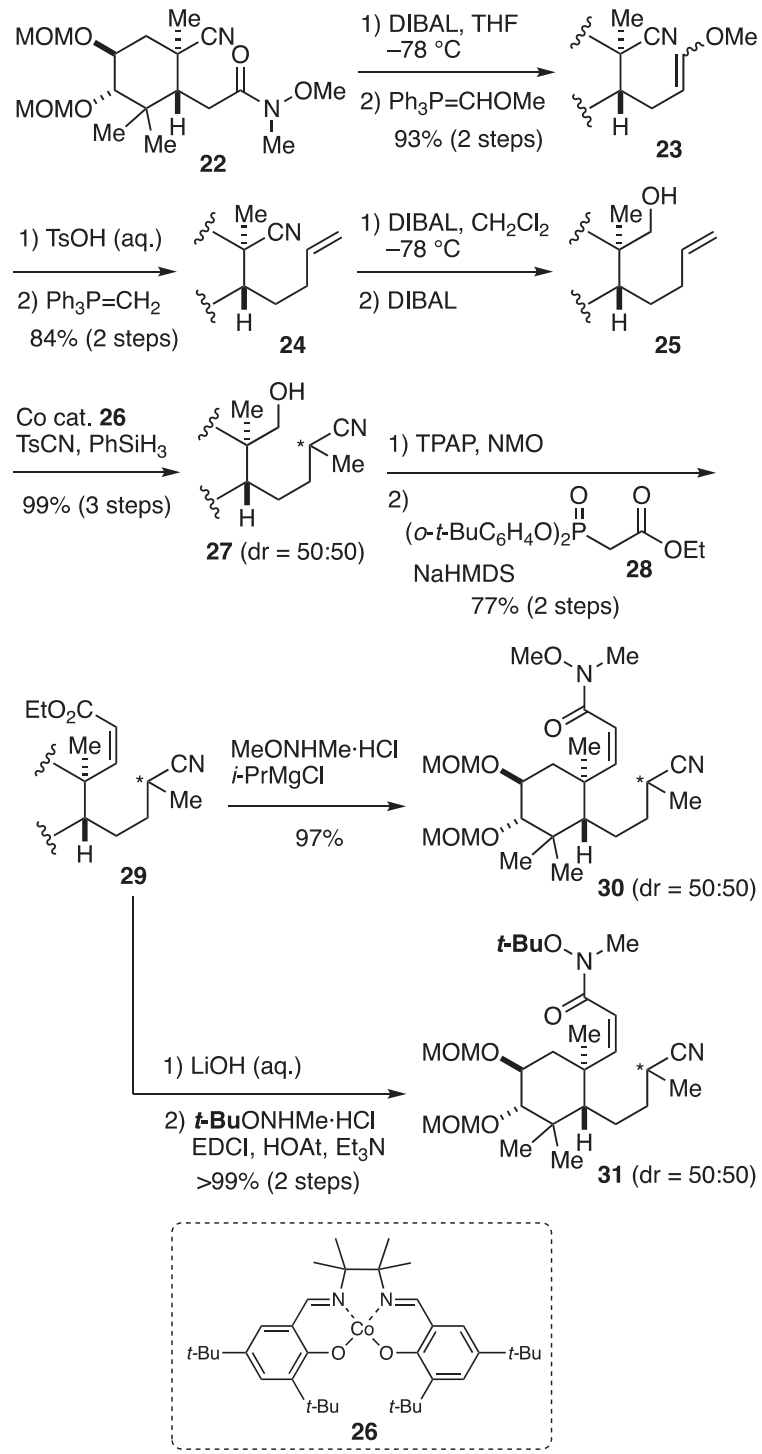

The second intramolecular nitrile Michael addition for the construction of the B-ring was another crucial step in the synthesis. We therefore carefully examined and optimized the reaction conditions, focusing on the solvent and additives for the cyclization of Weinreb amides $\mathbf{3 0}$ and $\mathbf{3 1}$ (Scheme 5). When the standard $O$-methyl Weinreb amide $\mathbf{3 0}$ was treated with NaHMDS in the presence of a bulky silylating agent, triisopropylsilyl chloride (TIPSCl) ${ }^{10}$ and hexamethylphosphoric triamide (HMPA) in THF at $-78{ }^{\circ} \mathrm{C}$, the intramolecular Michael addition proceeded smoothly to afford cyclic $O$-silyl $N, O-$ ketene acetal 32 in situ. Treatment of the reaction mixture with tetrabutylammonium fluoride (TBAF) in a one-pot manner gave a diastereomeric mixture of the desired cyclization product 33 and its C8,C9-diastereomer $\mathbf{3 4}^{20}$ in a 45:55 ratio (>99\% yield). In the absence of HMPA, the use of $\mathrm{Et}_{2} \mathrm{O}$ as a solvent led to an improved result, and a higher diastereoselectivity was observed ( $89 \%$ yield, $\mathbf{3 3 / 3 4}=80: 20)$.

Further optimization demonstrated that the steric repulsion between the large substituents in the cyclization precursor was the likely cause for the stereochemical outcome (Scheme 5). Thus, upon treatment of a mixture of the bulky $O$-tert-butyl Weinreb amide 31 and TIPSCl with NaHMDS in $\mathrm{Et}_{2} \mathrm{O}$ at $-78^{\circ} \mathrm{C}$, a highly diastereoselective intramolecular Michael addition occurred, producing $O$-silyl $N, O$-ketene acetal 35 in situ. Upon addition of TBAF to 35 , the desired cyclization product 36 was obtained as a 93:7 inseparable mixture with its C8,C9-diastereomer 37 (88\% yield). The addition of TIPSCl in this cyclization was crucial, because a lower diastereomeric ratio $(\mathbf{3 6} / \mathbf{3 7}=91: 9)$, as well as retro-addition to form unsaturated amide 31' $(E / Z=34: 66)$, were observed in the absence of TIPSCl. Presumably, the intramolecular Michael addition of 31 occurs preferentially via the transition state TS-2 with nonchelation control rather than the alternative transition state TS-3, to avoid steric repulsion between the two 1,3-diaxial methyl groups, as well as between the bulky tert-butoxy group of the Weinreb amide and the methyl group adjacent to the keteniminate in the transition state TS-3. The above two key nitrile Michael additions $(\mathbf{2 1} \rightarrow \mathbf{2 2}$ and $\mathbf{3 1} \rightarrow \mathbf{3 6})$ were reliably performed on a gram scale ( $>17 \mathrm{mmol}$ scale), which demonstrated the significant synthetic utility of this methodology.

\section{Stereoselective Synthesis of the Terpenoid Framework (ABC-ring)}

Having developed the method for generating the AB-ring including two quaternary asymmetric stereocenters, based on the strategic use of nitrile Michael additions, we next focused on the third intramolecular Michael addition, which leads to the ABC-ring of brasilicardins (Scheme 6). To this end, Weinreb amide 36 was converted to 1,1-dibromoalkene 39 bearing an $(E)-\alpha, \beta$-unsaturated ester moiety, the requisite cyclization precursor, in a four-step reaction sequence: 1) chemoselective reduction of the Weinreb amide moiety in $\mathbf{3 6}$ to an aldehyde using DIBAL in THF; 2) Corey-Fuchs dibromoolefination using $\mathrm{CBr}_{4}$ and $\mathrm{PPh}_{3}{ }^{21}$ after which the inseparable minor isomer 37 was separable; 3) reduction of the cyano group to an aldehyde, and 4) HWE olefination of the resulting aldehyde.

The next step was the methylative intramolecular Michael addition $^{12}$ for the construction of the $\mathrm{C}$-ring, critical to the synthesis (Scheme 6); hence this particular reaction was investigated thoroughly, in order to optimize the conditions. Pleasingly, optimized reaction conditions were established. Thus, upon treatment of 39 with $\mathrm{Me}_{2} \mathrm{CuLi}$ (5 equiv) in $\mathrm{Et}_{2} \mathrm{O}$ at $-78{ }^{\circ} \mathrm{C}$, tri-substituted vinyl copper intermediate $\mathbf{4 0}$ with a $(Z)$-configuration was generated in situ via selective methylation of the less hindered bromide. After the reaction mixture was warmed up to $-40{ }^{\circ} \mathrm{C}$ and then stirred at this temperature, the subsequent one-pot intramolecular conjugate addition to the $(E)-\alpha, \beta$-unsaturated ester moiety proceeded smoothly to give tricyclic compound $\mathbf{4 1}$ with complete control of the stereochemistry at the $\mathrm{C} 14$ position in $83 \%$ yield. The structure of 
Scheme 5. Construction of the B-ring.

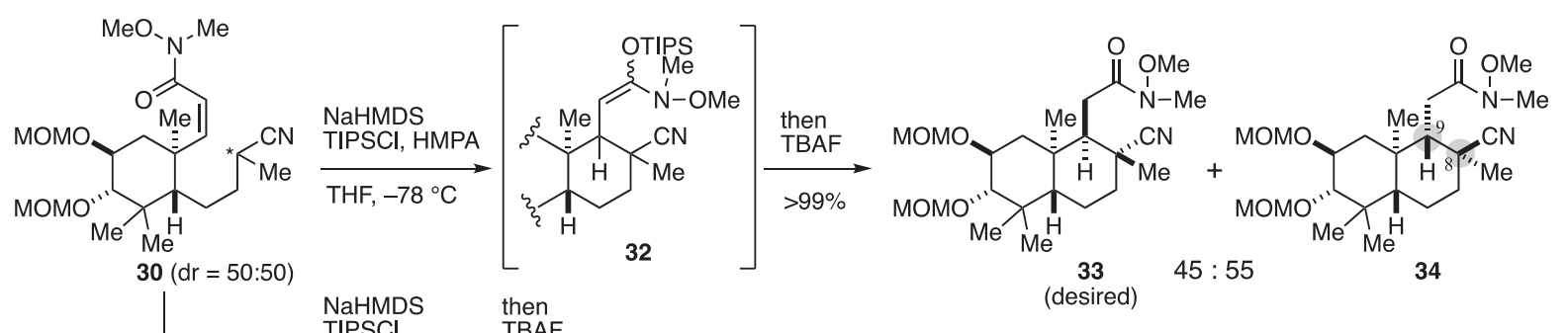

$3+34$

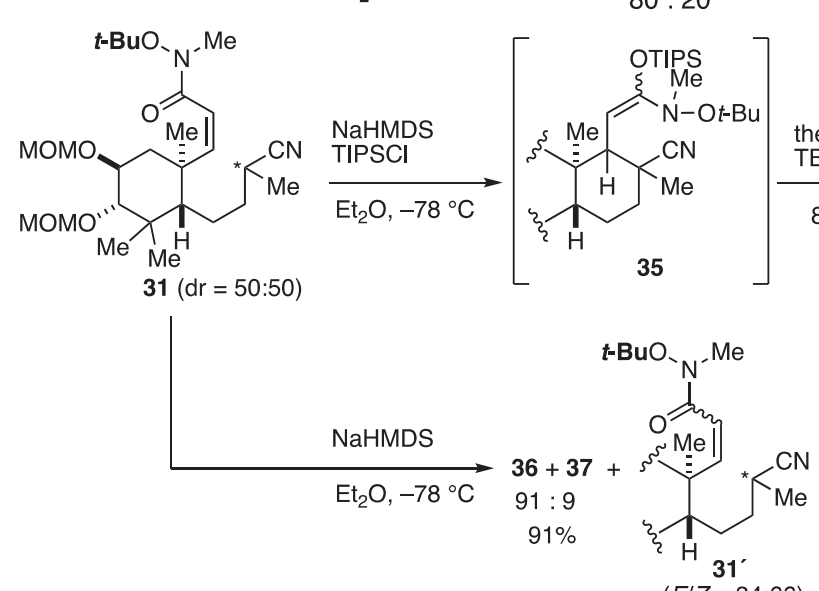

$(E / Z=34: 66)$

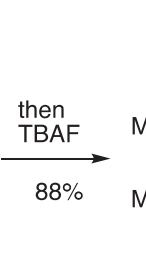

(ne)
41 was unambiguously confirmed by $\mathrm{X}$-ray crystallographic analysis (Scheme 6). In this manner, a new method for the stereoselective construction of the characteristic anti-syn-

Scheme 6. Construction of the C-ring.

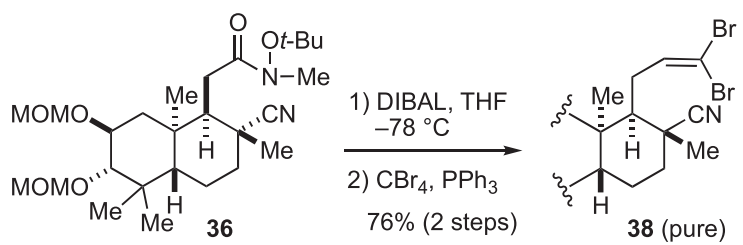
(93:7 mixure with 37 )

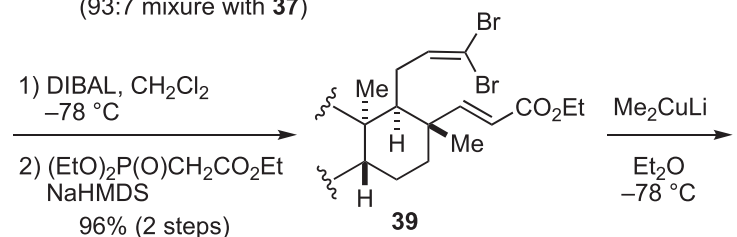

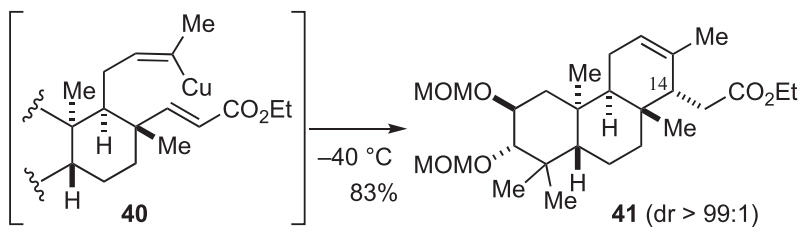

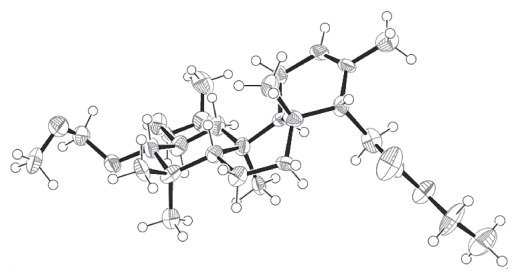

ORTEP of $\mathbf{4 1}$ ant $i$-fused perhydrophenanthrene diterpenoid carbon framework (the ABC-ring) was established, entailing triple intramolecular Michael additions as the key steps.

\section{Installation of the Amino Acid Component}

Having developed a method for the synthesis of the ABCring framework, our next objective was the installment of the appropriate amino acid component (Scheme 7). Initially, we focused on the stereoselective installation of the anti- $\beta^{-}$ methoxy- $\alpha$-amino acid for brasilicardins $\mathrm{A}$ and $\mathrm{C}$ (Scheme 7a). In pursuit of a straightforward synthesis of these components, we first investigated asymmetric aldol reactions of chiral glycine enolates ${ }^{22}$ or chiral chloroacetate enolates ${ }^{23}$ with the aldehyde derived from tricyclic ethyl ester $\mathbf{4 1}$; however, all attempts to obtain the desired anti- $\beta$-hydroxy- $\alpha$-amino acids were unsuccessful. Therefore, we directed our attention to a Sharpless dihydroxylation-based approach, ${ }^{24}$ which involved an asymmetric dihydroxylation and the subsequent nucleophilic substitution by a nitrogen nucleophile of a hydroxyl of the resulting chiral vicinal diol. Thus, the halfreduction of $\mathbf{4 1}$ with DIBAL, followed by the HWE reaction of the resulting aldehyde, yielded $(E)-\alpha, \beta$-unsaturated tertbutyl ester 42. Sharpless asymmetric dihydroxylation of $\mathbf{4 2}$ using the (DHQ)PHN-ligand ${ }^{14 a}$ gave the desired vicinal diol $\mathbf{4 3}$ as a single diastereomer. The C17-hydroxyl of diol ester $\mathbf{4 3}$ was regioselectively sulfonylated using 4-nitrobenzenesulfonyl chloride $(p-\mathrm{NsCl})$ and triethylamine to produce the corresponding mono-nosylate. Subsequent treatment with $\mathrm{NaN}_{3}$ afforded hydroxy azide $\mathbf{4 4}$ with complete inversion of configuration. $O$-Methylation of $\mathbf{4 4}$ with a Meerwein reagent $\left(\mathrm{Me}_{3} \mathrm{OBF}_{4}\right)$ followed by reduction of the azide with $\mathrm{SnCl}_{2}$ and subsequent protection of the resulting amine with a 9-fluore- 
Scheme 7. Installation of the amino acid component and conversion to the protected brasilicardin aglycons $\mathbf{4 5}$ and $\mathbf{5 0 .}$
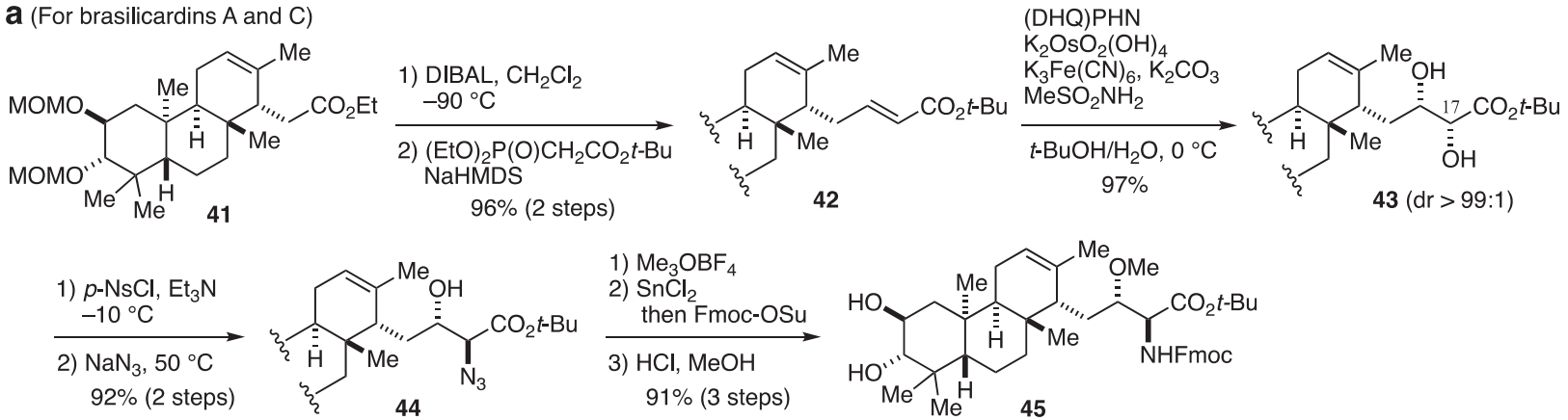

b (For brasilicardins B and D)

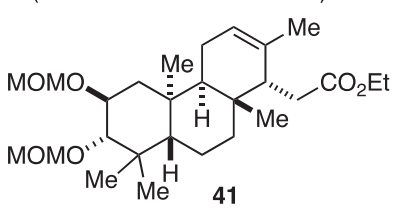

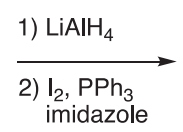
$98 \%(2$ steps)<smiles>CC[C@@H]1C(C)=CCC(CCC(N)C(=O)OC(C)(C)C)C1(C)CCC(N)C(C)(C)C</smiles><smiles>CCCC1(CC)CCC=C(C)[C@H]1CCI</smiles>

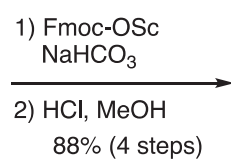<smiles>COC(=O)CN=C1C2CC3CC(C2)C1C3</smiles><smiles>CC(C)[Mg]</smiles>

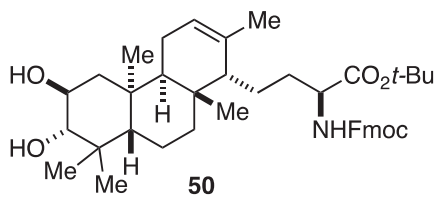<smiles>CCCC1(CC)C(C)CC=C(C)[C@H]1CCC(N=C1C[C@H]2C[C@H]1[C@@]2(C)O)C(=O)OC(C)(C)C</smiles>

nylmethyloxycarbonyl (Fmoc) group in a one-pot procedure, resulted in the formation of the protected amino acid moiety of brasilicardins A and C. Finally, removal of both MOM groups with $\mathrm{HCl}$ in methanol produced diol $\mathbf{4 5}$ (78\% yield, over eight steps from $\mathbf{4 1}){ }^{25}$

On the other hand, the installation of the amino acid components of brasilicardins $\mathrm{B}$ and $\mathrm{D}$ was achieved by asymmetric alkylation of a hydoxypinanone-derived chiral Schiff base ${ }^{26}$ as the key step (Scheme 7b). Thus, ethyl ester $\mathbf{4 1}$ was converted to alkyl iodide $\mathbf{4 6}$ via reduction with $\mathrm{LiAlH}_{4}$, followed by iodination of the resulting alcohol. Alkylation of the readily available chiral Schiff base $\mathbf{4 7}$ proceeded smoothly when potassium bis(trimethylsilyl)amide (KHMDS) was used as a base, resulting in the formation of the alkylation product $\mathbf{4 8}$ as a single diastereomer. ${ }^{27}$ This compound was successfully converted to diol $\mathbf{5 0}$ in three steps, involving removal of the chiral auxiliary group, Fmoc-protection of the resulting free-amine, and deprotection of the MOM groups ( $86 \%$ yield, over six steps from $\mathbf{4 1}$ ). The protected aglycons $\mathbf{4 5}$ and $\mathbf{5 0}$ were used in subsequent glycosylation studies.

\section{Stereoselective Glycosylation and Completion of Total Syntheses}

The final task in the synthesis was the challenging glycosylation of functionalized aglycons $\mathbf{4 5}$ and $\mathbf{5 0}$, culminating in the total synthesis of brasilicardins. First, the glycosylation of $\mathbf{4 5}$ toward brasilicardin A (1) was examined, as $\mathbf{1}$ was our primary target in this project. The requisite disaccharide glycosyl donors $\mathbf{5 3}$ and $\mathbf{5 4}$ were synthesized from the known hemiacetal $\mathbf{5 2}^{3 \mathrm{~b}}$ through fluorination with (diethylamino)sulfur trifluoride (DAST), ${ }^{29}$ and trichloroacetimidate formation, respectively, (Scheme 8). In anticipation of regioselective glycosylation at the less hindered $\mathrm{C} 2$-alcohol of diol $\mathbf{4 5}$, we initially attempted the reaction of $\mathbf{4 5}$ with trichloroacetimidate donor $\mathbf{5 4}$. Although the Anada and Hashimoto group succeeded in the glycosylation of the C3-protected aglycon of $\mathbf{1}$ with $\mathbf{5 4},{ }^{4}$ this powerful glycosylation method could not be applied to 45 as it led to the formation of complex mixtures, including the inseparable $\mathrm{C} 3$-glycosylation product and degradation products of 45. We next focused on the less reactive glycosyl fluoride donor 53. To our delight, after screening various activation conditions, it was established that the metallocene-promoted glycosylation procedure developed by Suzuki ${ }^{30}$ delivered optimal results (Scheme 9). Thus, in the presence of 2,6-di-tertbutyl-4-methylpyridine (DTBMP) as a buffer, 53 ( 2 equiv) was regioselectively coupled with $\mathbf{4 5}$ by treatment with $\mathrm{Cp}_{2} \mathrm{HfCl}_{2}$ and AgOTf to give the desired $\alpha$-glycoside $\mathbf{5 8}$ (with $43 \%$ recovered 45 ). In this reaction, the $\mathrm{C}^{2}$-acetate functionality in donor $\mathbf{5 3}$ guided the formation of the desired $\alpha$-glycoside via the transient acetoxonium ion intermediate 57. Because the prolonged reaction time caused an undesired reaction at the $\mathrm{C} 3$-alcohol, the coupling was terminated before complete consumption of $\mathbf{4 5}$, with recovery of unreacted $\mathbf{4 5}$. Finally, removal of tert-butyl ester in the glycosylation product 58 with trifluoroacetic acid (TFA), followed by global deprotection of the acetyl and Fmoc groups with ethylenedi-

Scheme 8. Synthesis of glycosyl donors $\mathbf{5 3 , 5 4}$, and $\mathbf{5 6}$.

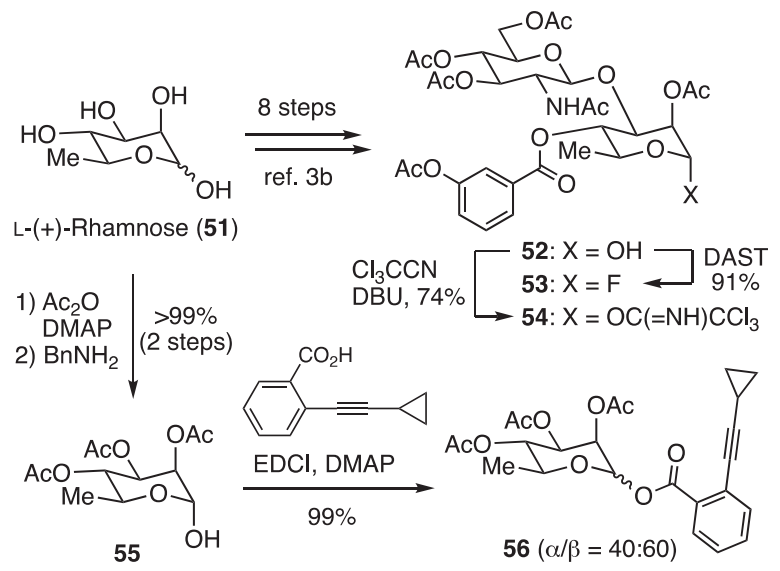


amine, furnished brasilicardin A (1) (43\% yield, over three steps). The spectral data $\left({ }^{1} \mathrm{H}\right.$ and ${ }^{13} \mathrm{C}$ NMR, IR, HRMS, and optical rotation) and melting point of synthetic 1 were identical to those of natural brasilicardin A (1). Brasilicardin B (2) was similarly synthesized from diol $\mathbf{5 0}$, via the same three-step reaction sequence employed for $\mathbf{1}$ (37\% yield, three steps).

Scheme 9. Total synthesis of brasilicardins A (1) and B (2).
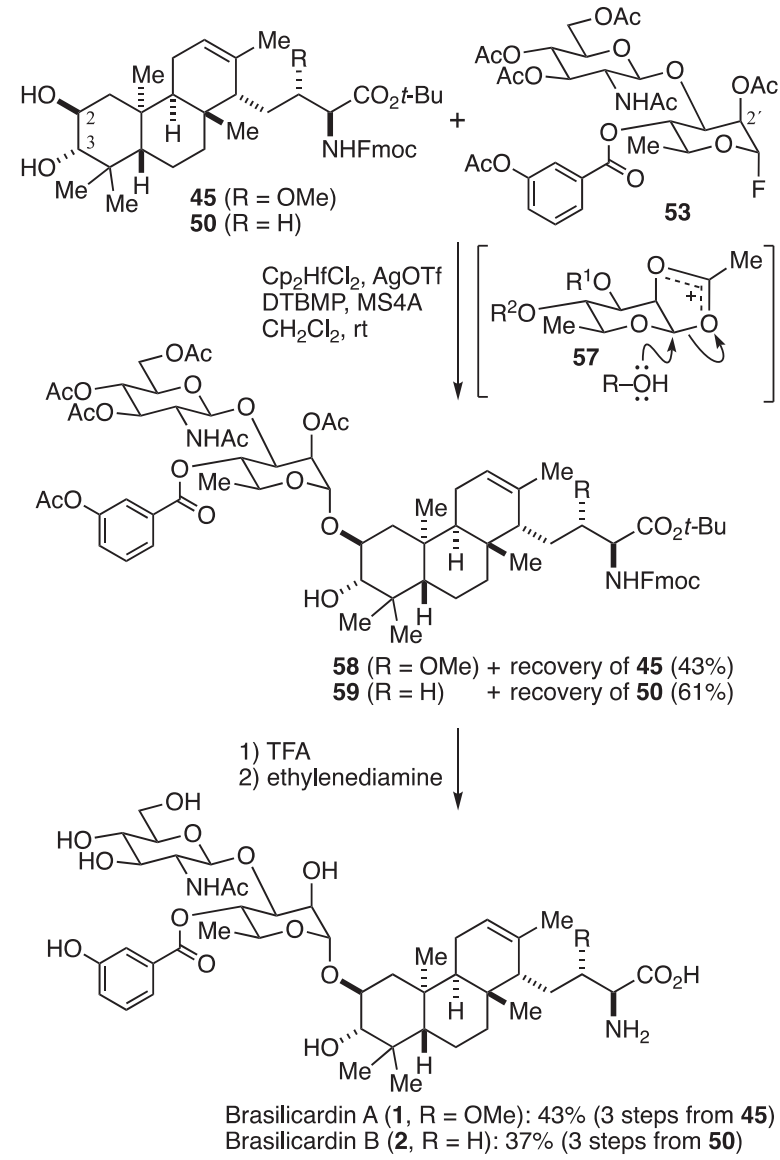

The achievement of the total syntheses of $\mathbf{1}$ and $\mathbf{2}$ prompted us to pursue the total syntheses of brasilicardins $\mathrm{C}$ (3) and D (4) (Scheme 10). In contrast to glycosylation with disaccharide 53, glycosylation of diol 45 with the peracetyl glycosyl fluoride donor derived from L-rhamnose did not show regioselectivity at the $\mathrm{C} 2$-alcohol; thus, C3-glycosylation and bis-glycosylation products were obtained, as well as the desired product. Glycosylation attempts with other donors were likewise unsuccessful. Accordingly, we decided to temporarily protect the $\mathrm{C} 3$-alcohol as a readily removable methoxyacetate, $^{31,32}$ and the requisite mono-alcohols $\mathbf{6 0}$ and $\mathbf{6 1}$ were synthesized from diols $\mathbf{4 5}$ and $\mathbf{5 0}$, respectively, via a three-step reaction sequence including 1 ) protection of the $\mathrm{C} 2$-alcohol with a bulky TBS group, 2) protection of the remaining C3alcohol with a methoxyacetyl group, and 3) selective removal of the TBS group with HF-pyridine. For the total synthesis of brasilicardin C (3), Yu's gold-catalyzed coupling ${ }^{33}$ of glycosyl $o$-cyclopropylethynylbenzoate 56 (1.5 equiv) (c.f., Scheme 8 for the synthesis of $\mathbf{5 6}$ ) with $\mathbf{6 0}$ proved to be the most effective method for the stereoselective installation of a rhamnose unit, providing the glycosylation product $\mathbf{6 2}$ in excellent yield. ${ }^{34}$ This compound was successfully converted to brasilicardin C (3) ( $94 \%$ yield, three steps) through TFA-mediated removal of the tert-butyl ester and the subsequent global deprotection of the remaining acetyl, methoxyacetyl, and Fmoc groups with aqueous lithium hydroxide solution. Additionally, brasilicardin D (4) was synthesized from mono-alcohol $\mathbf{6 1}$ via the same reaction sequence as employed for $\mathbf{3}$ ( $92 \%$ yield, three steps). In this manner, we accomplished the first total syntheses of brasilicardins B (2) and D (4), in addition to the total syntheses of brasilicardins A (1) and C (3).

Scheme 10. Total synthesis of brasilicardins C (3) and D (4).

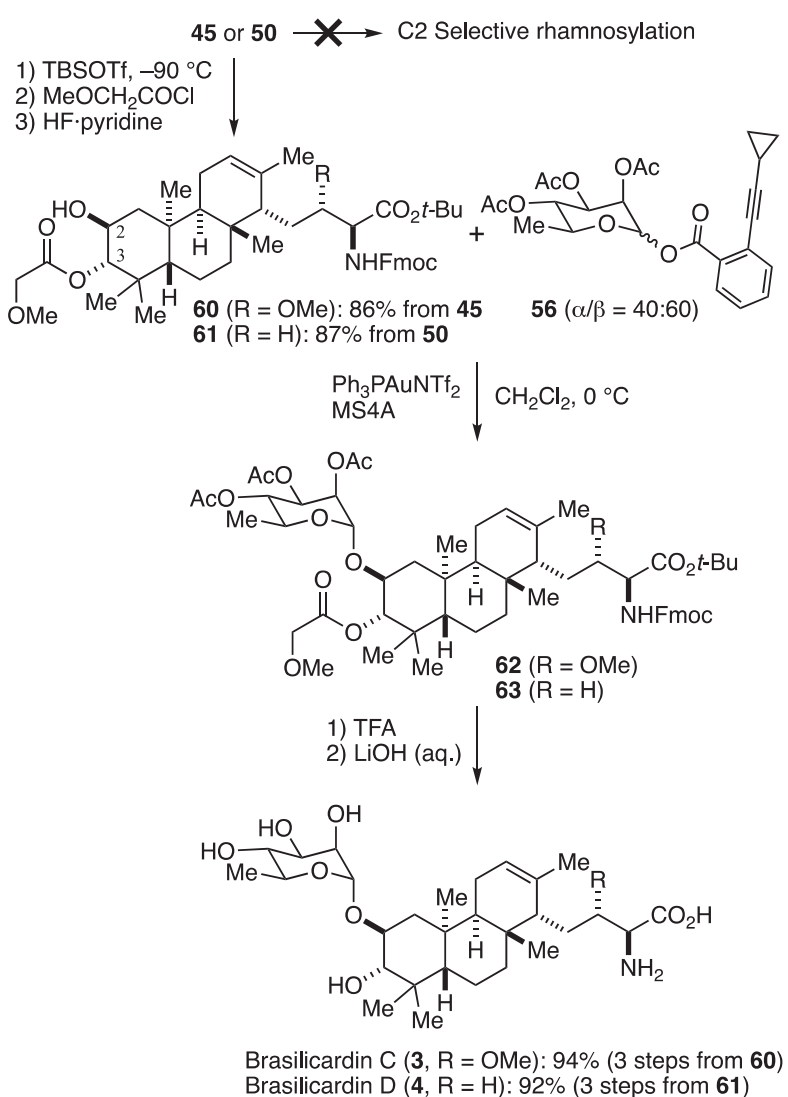

\section{Conclusions}

We have developed stereoselective synthetic routes to brasilicardins $\mathrm{A}-\mathrm{D}$, which are hybrids of terpenoids, amino acids, and saccharides, and exhibit potent immunosuppressive activity. We have accomplished the asymmetric total synthesis of brasilicardin A (39 linear steps), brasilicardin B (37 linear steps), brasilicardin C (42 linear steps), and brasilicardin D (40 linear steps) from commercially available materials. Our synthetic approach features: 1) the development of a novel intramolecular nitrile Michael addition, namely, stereoselective intramolecular conjugate addition of an $\alpha$-cyano carbanion to an $\alpha, \beta$-unsaturated Weinreb amide, which accomplishes simultaneous ring formation and the construction of contiguous quaternary-tertiary asymmetric stereocenters; 2) a Michael addition-based strategy for the stereoselective construction of the highly strained anti-syn-anti-fused perhydrophenanthrene framework; 3) stereoselective installation of the amino acid component to the terpenoid framework; and 4) regio- and stereoselective glycosylation with the appropriate sugar units. Our strategy enables the unified synthesis of all brasilicardins from a common late-stage synthetic intermedi- 
ate, through the implementation of appropriate methods for glycosylation and the installation of amino acids. The novel synthetic routes developed herein will likewise contribute to the rationalization of the biological effects of brasilicardins at the molecular level, and to the elucidation of their pharmacophore, which is potentially applicable in the development of new immunosuppressive drugs.

\section{Acknowledgements}

We acknowledge, and express gratitude to Professors Jun'ichi Kobayashi (Hokkaido University) and Takaaki Kubota (Showa Pharmaceutical University) for providing an authentic sample of natural brasilicardin A. The authors thank Professor Hideyuki Shigemori (University of Tsukuba) and Dr. Hisayuki Komaki (NBRC) for helpful discussions regarding the purification protocols of brasilicardins. Additionally, we acknowledge the assistance received from the late Professor Tamotsu Inabe and Dr. Takahiro Suzuki (Hokkaido University) with the $\mathrm{X}$-ray structural analysis. This work was supported by JSPS KAKENHI Grant Numbers JP22710206, JP24510290, JP15K01795, JP18K05339, JP18H01970, and JP15H05842 in Middle Molecular Strategy.

\section{References}

1) (a) Shigemori, H.; Komaki, H.; Yazawa, K.; Mikami, Y.; Nemoto, A.; Tanaka, Y.; Sasaki, T.; In, Y.; Ishida, T.; Kobayashi, J. J. Org. Chem. 1998, 63, 6900. (b) Komaki, H.; Nemoto, A.; Tanaka, Y.; Takagi, H.; Yazawa, K.; Mikami, Y.; Shigemori, H.; Kobayashi, J.; Ando, A.; Nagata, Y. J. Antibiot. 1999, 52, 13. (c) Komaki, H.; Tanaka, Y.; Yazawa, K.; Takagi, H.; Ando, A.; Nagata, Y.; Mikami, Y. J. Antibiot. 2000, 53, 75. (d) Komatsu, K.; Tsuda, M.; Shiro, M.; Tanaka, Y.; Mikami, Y.; Kobayashi, J. Bioorg. Med. Chem. 2004, 12, 5545.

2) Usui, T.; Nagumo, Y.; Watanabe, A.; Kubota, T.; Komatsu, K.; Kobayashi, J.; Osada, H. Chem. Biol. 2006, 13, 1153.

3) (a) Coltart, D. M.; Danishefsky, S. J. Org. Lett. 2003, 5, 1289. (b) Jung, M. E.; Koch, P. Org. Lett. 2011, 13, 3710. (c) Jung, M. E.; Perez, F.; Regan, C. F.; Yi, S. W.; Perron, Q. Angew. Chem. Int. Ed. 2013, 52, 2060. (d) Jung, M. E.; Chamberlain, B. T.; Koch, P.; Niazi, K. R. Org. Lett. 2015, 17, 3608.

4) Anada, M.; Hanari, T.; Kakita, K.; Kurosaki, Y.; Katsuse, K.; Sunadoi, Y.; Jinushi, Y.; Takeda, K.; Matsunaga, S.; Hashimoto, S. Org. Lett. 2017, 19, 5581.

5) Yoshimura, F.; Itoh, R.; Torizuka, M.; Mori, G.; Tanino, K. Angew. Chem. Int. Ed. 2018, 57, 17161.

6) For recent reviews, see: (a) Justicia, J.; de Cienfuegos, L. Á.; Campaña, A. G.; Miguel, D.; Jakoby, V.; Gansäuer, A.; Cuerva, J. M. Chem. Soc. Rev. 2011, 40, 3525. (b) Barrett, A. G. M.; Ma, T.; Mies, T. Synthesis 2019, $51,67$.

7) Nishizawa, M.; Takenaka, H.; Hirotsu, K.; Higuchi, T.; Hayashi, Y. $J$. Am. Chem. Soc. 1984, 106, 4290.

8) Balasubramaniam, S.; Aidhen, I. S. Synthesis 2008, 3707.

9) (a) Byrd, K. M. Beilstein J. Org. Chem. 2015, 11, 530. (b) Arseniyadis, S.; Kyler, K. S.; Watt, D. S. Org. React. 1984, 31, 1.

10) Yoshimura, F.; Torizuka, M.; Mori, G.; Tanino, K. Synlett 2012, 23, 251.

11) Eliel, E. L.; Wilen, S. H.; Mander L. N. Stereochemistry of Organic Compounds; Wiley: New York, 1994, pp 696-697.

12) Tanino, K.; Arakawa, K.; Satoh, M.; Iwata, Y.; Miyashita, M. Tetrahedron Lett. 2006, 47, 861 .

13) Blanchette, M. A.; Choy, W.; Davis, J. T.; Essenfeld, A. P.; Masamune, S.; Roush, W. R.; Sakai, T. Tetrahedron Lett. 1984, 25, 2183.

14) (a) Sharpless, K. B.; Amberg, W.; Beller, M.; Chen, H.; Hartung, J.; Kawanami, Y.; Lübben, D.; Manoury, E.; Ogino, Y.; Shibata, T.; Ukita, T. J. Org. Chem. 1991, 56, 4585. (b) Ohmori, K.; Nishiyama, S.; Yamamura, S. Tetrahedron Lett. 1995, 36, 6519.

15) Ley, S. V.; Norman, J.; Griffith, W. P.; Marsden, S. P. Synthesis 1994, 639.

16) Gaspar, B.; Carreira, E. M. Angew. Chem. Int. Ed. 2007, 46, 4519

17) (a) Ando, K. J. Org. Chem. 1997, 62, 1934. (b) Touchard, F. P.; Capelle, N.; Mercier, M. Adv. Synth. Catal. 2005, 347, 707.

18) Williams, J. M.; Jobson, R. B.; Yasuda, N.; Marchesini, G.; Dolling,
U.; Grabowski, E. J. J. Tetrahedron Lett. 1995, 36, 5461.

19) Labeeuw, O.; Phansavath, P.; Genêt, J. Tetrahedron Lett. 2004, 45, 7107.

20) Interestingly, intramolecular Michael addition of the corresponding (E)-isomer of $\alpha, \beta$-unsatured Weinreb amide $\mathbf{3 0}$ exclusively gave $\mathbf{3 4}$ ( $88 \%$ yield). See, Scheme S2 in the supporting information of ref. 5.

21) Corey, E. J.; Fuchs, P. L. Tetrahedron Lett. 1972, 3769.

22) (a) Li, Q.; Yang, S.; Zhang, Z.; Li, L.; Xu, P. J. Org. Chem. 2009, 74 1627. (b) Adachi, M.; Imazu, T.; Sakakibara, R.; Satake, Y.; Isobe, M.; Nishikawa, T. Chem. Eur. J. 2014, 20, 1247.

23) (a) Evans, D. A.; Sjogren, E. B.; Weber, A. E.; Conn, R. E. Tetrahedron Lett. 1987, 28, 39. (b) Hirose, T.; Sunazuka, T.; Tsuchiya, S.; Tanaka, T.; Kojima, Y.; Mori, R.; Iwatsuki, M.; Ōmura, S. Chem. Eur. J. 2008, $14,8220$.

24) Rama Rao, A. V.; Chakraborty, T. K.; Laxma Reddy, K.; Srinivasa Rao, A. Tetrahedron Lett. 1994, 35, 5043.

25) Stereochemistry of the amino acid component was verifid by $\mathrm{X}$-ray crystallographic analysis after converison to the corresponding $p$-bromobenzamide derivative of 45. For details, see ref. 5.

26) Yamada, S.; Oguri, T.; Shioiri, T. J. Chem. Soc., Chem. Commun. 1976, 136.

27) Stereochemistry of the amino acid moiety was confirmed by the modified Mosher's method. ${ }^{28}$ For details, see ref. 5 .

28) (a) Ohtani, I.; Kusumi, T.; Kashman, Y.; Kakisawa, H. J. Am. Chem Soc. 1991, 113, 4092.; (b) Kusumi, T. J. Synth. Org. Chem., Jpn. 1993, $51,462$.

29) (a) Rosenbrook, W.; Riley, D. A.; Lartey, P. A. Tetrahedron Lett. 1985 , 26, 3. (b) Posner, G. H.; Haines, S. R. Tetrahedron Lett. 1985, $26,5$.

30) (a) Suzuki, K.; Maeta, H.; Matsumoto, T. Tetrahedron Lett. 1989, 30, 4853. (b) Suzuki, K.; Matsumoto, T. J. Synth. Org. Chem., Jpn. 1993, 51,718 .

31) Reese, C. B.; Stewart, J. C. M.; van Boom, J. H.; de Leeuw, H. P. M.; Nagel, J.; de Rooy, J. F. M. J. Chem. Soc., Perkin Trans. 1 1975, 934.

32) We also attempted the protection of the $\mathrm{C} 3-$ alcohol as its acetate, but it could not be removed without epimerization of the amino acid moiety.

33) (a) Li, Y.; Yang, Y.; Yu, B. Tetrahedron Lett. 2008, 49, 3604. (b) Yu, B. Acc. Chem. Res. 2018, 51, 507.

34) The metallocene-promoted glycosylation of $\mathbf{6 2}$ with the corresponding peracetyl glycosyl fluoride donor, analogous to that with 53, resulted in significantly lower conversion. 


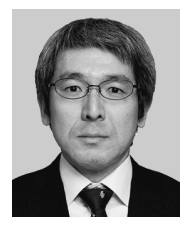

Fumihiko Yoshimura studied chemistry at Tohoku University (B.S., 1996; Ph.D., 2002, with Prof. Masahiro Hirama). After receiving his Ph.D., he moved to the United States and completed a postdoctoral appointment at the Sloan-Kettering Institute for Cancer Research (2002-2004, Prof. Samuel J. Danishefsky). In 2004, he joined the Faculty of Science at Hokkaido University as an assistant professor (the group of Prof. Masaaki Miyashita and Prof. Keiji Tanino). He has been an associate professor at the University of Shizuoka since 2017 (the group of Prof. Toshiyuki Kan). His research interests include the total synthesis of polyfunctional, biologically active natural products and the development of new reactions.

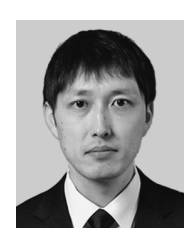

Ryusei Itoh is a research scientist at the Process Technology Research Laboratories, Pharmaceutical Division, Daiichi Sankyo Company, Limited. He obtained his bachelor's degree (2014), master's degree (2016), and Ph.D. degree in Science (2019) from Hokkaido University under the supervision of Prof. Keiji Tanino. He received the Poster Presentation Award of the 28th Banyu Sapporo Symposium (2016). His current research interests are in the areas of medicinal chemistry and process chemistry.

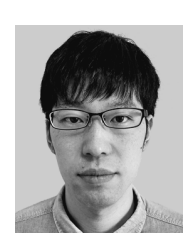

Makoto Torizuka received his bachelor's degree (2011), master's degree (2013) in Science from Hokkaido University under the supervision of Prof. Keiji Tanino. In 2013, he joined Japan Tobacco Inc., where he is currently a researcher. His current research interests are in the areas of medicinal chemistry.

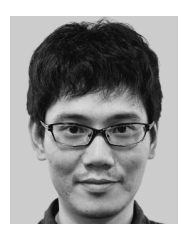

Genki Mori has been a research scientist at the Central Pharmaceutical Research Institute, Chemical Research Laboratories, Japan Tobacco Inc. since 2011. He received his B.S. (2009) and M.S. degrees (2011) from Hokkaido University under Prof. Keiji Tanino. He has been a visiting researcher at Nagoya University (Prof. Kenichiro Itami group) between 2018 and 2020. His research interests are late stage $\mathrm{C}-\mathrm{H}$ functionalization for drug discovery.

Keiji Tanino is a Professor at Hokkaido University. $\mathrm{He}$ received his B.S. in 1985 and his M.D. in 1987 from the Tokyo Institute of Technology under the direction of Professor Isao Kuwajima. He was appointed as an assistant professor of Kuwajima's group at the Tokyo Institute of Technology in 1989 and received his Ph.D. in 1994 from the Institute. In 1998, he joined the Department of Chemistry, Hokkaido University, and was promoted to associate professor in 1999 and then professor in 2006. His research interests are centered on the development of highly selective $\mathrm{C}-\mathrm{C}$ bond-forming reactions and the total synthesis of complex natural products. 